\title{
Una investigación sobre migración en el marco de la seguridad humana
}

\author{
Investigating migration within a human security framework
}

\author{
Des Gasper* \\ Giulia Sinatti**
}

\begin{abstract}
RESUMEN: La migración es una búsqueda de seguridad y a la vez un acto que expone a una persona a nuevos tipos de inseguridad, en especial a los migrantes internacionales. Se argumenta, entonces, que el enfoque de la seguridad humana en la investigación de los temas migratorios puede brindar percepciones adicionales, pues se centra en los migrantes y en las personas, al investigar sistemáticamente oportunidades y vulnerabilidades de personas complejas. La seguridad humana añade una ontología que justifica de mejor manera la explicación, la evaluación y el análisis de diversas políticas. La revisión de la literatura de las dos áreas (la seguridad humana y los estudios de migración) permite revelar los problemas. El documento aborda lagunas y debilidades en cuanto a la perspectiva de género en los estudios sobre migración. Si bien un marco de seguridad humana no es considerado esencial en la investigación, puede abordar elementos relevantes, valiosos o distintivos, relacionados con el tópico de la seguridad común.
\end{abstract}

PALABRAS CLAVE: migración internacional, seguridad humana, capacidad, vulnerabilidad.

ABSTRACT: Migration is both a quest for security, and an act that exposes one to new kinds of insecurity, especially for international migrants. We argue that a human security approach to researching migration issues can provide additional insights. It is migrant-centered and person-centered, systematically investigating the opportunities and vulnerabilities of complex persons. Human security adds an ontology that better grounds the work of explanation, evaluation and policy analysis. A literature review of the two areas (human security and migration studies) aids in revealing the issues at hand. The paper addresses gaps and weaknesses in the gender component of migration studies. A human security framework is not viewed as essential to the research, but may broach relevant, valuable and distinctive elements relating to theme of common security.

KEY WORDS: international migration, human security, capability, vulnerability.

\footnotetext{
* International Institute of Social Studies (ISS) of Erasmus University Rotterdam.

** Department of Social \& Cultural Anthropology, Free University of Amsterdam. Traducido del inglés por Jorge Miguel Veizaga Rosales.
} 



\title{
Introducción: un enfoque centrado en los migrantes $-y$ en las personas- desde una perspectiva global
}

\author{
«La voz del migrante se oye rara vez» (Benton, 2013: IX).
}

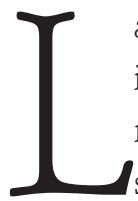

a migración se genera en parte debido a una búsqueda de seguridad e implica nuevos tipos y riesgos de inseguridad. Inseguridad para los migrantes y para los migrantes internacionales en particular, quienes son extranjeros en muchos sentidos, incluyendo el caso de la identidad frente a los sistemas administrativos, la familiaridad cultural y la aceptación política y cultural. En años recientes un número importante de trabajos han usado la perspectiva de la seguridad humana para explorar la migración interna y especialmente la migración internacional. ${ }^{1}$ Este artículo se concentra en la esencia de esos trabajos y en sus posibles resultados, límites y relaciones con las corrientes asociadas. ${ }^{2}$

Tradicionalmente, el enfoque en el estudio de la migración ha sido dominado por intereses políticos y preocupaciones de los países que reciben a los migrantes. En su estructura los estudios migratorios a menudo estaban dominados por la búsqueda de modelos universales convencionales basados en regularidades de comportamiento y por una cierta ausencia de interés en las diversas complejidades de las vidas de los migrantes, sin mencionar siquiera sus pensamientos y sentimientos; era un tipo de estudio que reflejaba los formatos convencionales de la economía y la macrosociología (Arango, 2000). En las últimas décadas, en dichos estudios se han realizado diversos esfuerzos para trascender los aspectos mencionados. La investigación desde el transnacionalismo, por ejemplo, ha puesto en un primer plano una profunda comprensión de los migrantes, así como de las redes y las comunidades en las que se insertan y que se extienden más

${ }^{1}$ Véase la Comisión sobre la Seguridad Humana (2003), Mushakoji y Pasha (2008), Edwards y Ferstman (2010), Eriksen et al. (2010), Truong y Gasper (2008, 2011), Truong et al. (2014) y Journal on Migration and Human Security (http://jmhs.cmsny.org/index.php/jmhs/about), entre otros.

${ }^{2}$ Quisiéramos agradecer a nuestro colega ya retirado Thanh-Dam Truong por sus valiosos comentarios a este artículo y por habernos inspirado durante muchos años. 
allá de las fronteras de los países de destino (u origen), lo que ha ayudado a descubrir aquello que no se reconocía en el pensamiento convencional acerca de la migración. Algunos intentos recientes orientados a integrar la teoría sobre migración con elementos de la corriente de pensamiento en torno de capacidades en los estudios del desarrollo (De Haas, 2010, 2014) buscan reconocer tanto a la «estructura» como a la "agencia», al mismo tiempo que confrontan las limitaciones de esas categorías.

En este artículo planteamos que el enfoque de seguridad humana puede contribuir a lo expuesto con la finalidad de proponer comprensiones adicionales. Este enfoque plantea la centralidad del migrantey, de manera más general, la centralidad de la persona, además de ofrecer un tipo de análisis más holístico y antropológico. Se combina la centralidad de la persona con una forma sistémica de investigar las oportunidades y las vulnerabilidades de personas complejas, junto con un marco global para la explicación y la evaluación. A diferencia de la afirmación de los juicios de valor acerca de la importancia de las personas, el enfoque de la seguridad humana añade el elemento ontológico al considerar la totalidad de las interconexiones entre las personas, sus necesidades físicas y psicológicas y sus motivaciones. Todo ello consolida el trabajo de explicación, evaluación y análisis político.

La siguiente sección sintetiza algunas variantes de la teoría de la seguridad humana. A partir de una revisión bibliográfica se exponen las contribuciones de análisis de la seguridad humana en los estudios migratorios. Entre ellos se incluye valorar las intersecciones entre desposesión y vulnerabilidad; el estudio de las interrelaciones entre campos usualmente separados y el modo en que varios aspectos de la inseguridad humana interaccionan; una descripción psicológica más compleja de los actores humanos que ayuda a reflexionar sobre categorías centrales, en especial aquellas relacionadas con las «comunidades», identidades y naciones, cuya evolución ha sido influida por la migración. Una sección paralela se concentra en cómo la perspectiva de la seguridad humana puede contribuir al análisis de la política y a la gobernanza de la migración.

Así como el artículo destaca las contribuciones del análisis de la seguridad humana en los estudios migratorios, el artículo también discute sus vacíos, debilidades y las áreas para el trabajo futuro o la necesidad de asociación con 
otros enfoques relativos a las condiciones de vida, bienestar, análisis de capacidades y derechos humanos. Asimismo, el análisis de la seguridad humana en la migración debería abordar lo "humano» desde una perspectiva de género. Cabe mencionar que gran parte de la teoría migratoria ha sido incapaz de aproximarse a las cuestiones de género (Pessar y Mahler, 2003). Los aspectos primordiales de un enfoque de seguridad humana tienen que ver con la amplia atención a la intersección entre factores estructurales y contingentes que generan vulnerabilidades y oportunidades en la vida de la gente común, por lo que tales aspectos permiten una asociación con el feminismo. En general, el artículo no afirma que el enfoque de seguridad humana sea esencial en las principales aportaciones identificadas, cada una de las cuales puede encontrarse en uno o más enfoques; pero sí sugiere que la perspectiva de la seguridad humana ofrece una integración valiosa y motivadora. Complementariamente, brinda varios elementos distintivos, incluyendo el importante tema de la seguridad común.

\section{La perspectiva de la seguridad humana}

\section{Una consideración inicial}

La perspectiva analítica de la seguridad humana es más bien un marco de trabajo general para orientar la atención, pues no se trata de un modelo teórico preciso. Este marco analítico contiene elementos esenciales y otros totalmente opcionales. En ocasiones, en la última categoría se encuentran disponibles opciones que se oponen entre sí y esto también podría suceder en el caso de ciertos elementos típicos pero no-esenciales. Por lo tanto, existen muchas versiones. ${ }^{3}$

Dos elementos esenciales corresponden al tema de lo «humano»: un interés evaluativo respecto de la vida de todas las personas y uno explicativo que

\footnotetext{
${ }^{3}$ La resolución aprobada por la Asamblea General de las Naciones Unidas 66/290 de 2012 presenta una formulación básica que enfatiza los valores de los derechos humanos, un enfoque de política «centrado en la gente, comprehensivo, orientado a contextos específicos y a la prevención» y una preocupación en las interconexiones entre la paz, el desarrollo y los derechos humanos.
} 
implica la observación de las personas como individuos. El marco analítico se enfoca en las personas en ambos sentidos. Concerniente a la evaluación incluye un compromiso con la dignidad humana y con los derechos humanos, y una concentración en la seguridad de la gente, objetiva y subjetiva, antes que en la seguridad del Estado, la seguridad nacional o la seguridad de la economía. No obstante, una característica del enfoque es que dicho compromiso no es exclusivo ni absoluto con las convenciones internacionales de derechos humanos, ya que los valores de los derechos humanos no son los únicos que existen y pueden entrar en conflicto unos con otros.

En lo relativo a la descripción y la explicación, el marco analítico comprende el rechazo al nacionalismo metodológico, el cual contempla a los países como las principales unidades de análisis (y a veces como a los actores principales) (Gore, 1996; Glick y Schiller, 2010). El nacionalismo refleja el sistema westphaliano de poder y valor y también supone poblaciones sedentarias (Bakewell, 2008). El análisis de la seguridad humana contiene el individualismo metodológico (o mejor dicho, personalismo, centrado en la persona) y un globalismo metodológico, una marcada atención a las influencias que cruzan las fronteras. ${ }^{4}$ El centro de atención se halla en las vidas genuinas y no en actores abstractos: no simplemente "gente» o «el migrante», sino personas de una edad específica, sexo, familia, etnicidad, contexto, patrimonio, que llevan consigo experiencias y cultura. Una parte del debate en torno a la migración utiliza lenguaje impersonal deshumanizado (como «flujos»" $)$ y nunca trata a las personas en específico ni a las historias de vida, o incluso localidades específicas y tipos de personas. Por ejemplo, la investigación sobre cambio climático y migración tal vez no ha considerado de modo suficiente las diferentes situaciones de hombres, mujeres y niños, cada uno con miles de tipos. El debate de la seguridad humana, en contraste, se caracteriza por tener una orientación antropológica holística que explora la especificidad, la diversidad y la complejidad.

\footnotetext{
${ }^{4}$ En este caso, la seguridad humana trasciende el término usado por Haas (2014) para definir la teoría transnacional: «Interaccionista simbólico». Además, el término fue el histórico nombre para una línea particular en un enfoque de trabajo más amplio que él quería describir.

${ }^{5}$ Véase lenguaje y argumentación en el Informe Mundial de Migración (IOM, 2008), analiza-do en Campillo, Carrete y Gasper (2011).
} 
El término «seguridad» en el discurso de la seguridad humana fue adoptado porque desde hace mucho tiempo ha sido usado por grupos que controlan el Estado nación para definir y asegurar la prioridad de algunos grupos y valores y no otros; normalmente se priorizan los intereses del Estado y los de los grupos de grandes propietarios. En cambio, la terminología de la «seguridad humana» asigna ese estatus prioritario a los derechos humanos básicos y a las necesidades de todos, sin perder de vista las funciones fundamentales del poder, incluyendo la manera en que éste circula a través del Estado. Un elemento adicional es la preocupación por la provisión estable de los elementos básicos ya mencionados. Así, la preocupación por la estabilidad es en realidad la preocupación por lo básico y no la estabilidad per se, menos aún la estabilidad de una situación injusta.

En la intersección de los temas de lo «humano» y de la «seguridad» existe un componente importante que alude a las dimensiones de sentido y de la seguridad emocional y existencial de las personas. Esto se aprecia en el discurso de «libertad para vivir con dignidad». Otro aspecto característico se encuentra en la atención a las interacciones entre violencia y desarrollo económico, junto con las relacionadas con cuestiones de dignidad e indignidad. También se ha prestado atención de modo más general a los nexos inter-sectoriales e interdisciplinares, tal como en realidad se experimentan en la vida de la gente. Metodológicamente, esto lleva a un enfoque situacional: se observa caso por caso para ver qué vínculos son más «vívidos» y qué prioridades se consideran más amenazadas.

Este tipo de abordaje y agenda no son nuevos. Es posible encontrarlos en la tradición de la antropología sociocultural, en el ámbito de la ecología humana y los estudios contemporáneos de cambio socioecológico, además de algunos estudios sobre la paz y el conflicto y en los estudios críticos de seguridad. Dicho enfoque adquirió un nuevo espacio e impulso al asociarse al trabajo del Desarrollo Humano propuesto por Mahbub ul Haq y otros en la era posterior a la Guerra Fría (Haq, 1999). ${ }^{6}$ Las grandes ambiciones del enfoque de la seguridad humana lo convirtieron en una incómoda y sospechosa presencia dentro

${ }^{6}$ Véase Oberleitner (2012) y Vietti y Scribner (2013) a propósito de la emergencia histórica de esos temas, sobre todo en los años 1940, 1980 (en los informes de la Comisión Brandt y de la Comisión Palme) y 1990. 
de las burocracias gubernamentales y la academia. Empero, atrajo a quienes fueron marginados por esas estructuras de poder.

\section{Cuatro escalas}

La reflexión acerca de la seguridad humana ha sido planteada en varias escalas:

1. Como un conjunto de valores/criterios/objetivos.

2. Como un abordaje especial para analizar problemas/realidades humanas/sociales.

3. Como un abordaje especial para el análisis de la política.

4. Como una posición política particular o una perspectiva sobre la gobernanza.

Las cuatro escalas se hallan en orden creciente de ambición. La primera es la fundamental. Las demás resultan menos claras progresivamente, en especial 3 y 4; es posible encontrar mayor diversidad de pensamiento aquí y tanto mayor cuando se pasa de la escala 2 a la 4 . La idea de la seguridad humana se enfoca y origina en la escala 1 y mientras esa idea/valor tiende a reflejar o conduce a ciertos tipos de concepción de las personas, sociedad humana y Estados, inclusive acerca de la política y la gobernanza, no está totalmente atada a ninguno de los otros tipos de concepciones, ya sea histórica o lógicamente. Por ende, no se puede elegir una sola concepción, la idea de la seguridad humana contiene diferentes versiones.

Todas las escalas se observan en los estudios migratorios, en concreto las primeras dos, las cuales son tratadas en esta sección y en la siguiente, respectivamente. Por lo general, los migrantes han sido demasiado débiles y marginales de manera que su seguridad o inseguridad depende en gran medida de la política existente, del diseño de políticas o de los sistemas de gobierno. A pesar de que las implicaciones de un enfoque de seguridad humana en la política y la gobernanza ya han sido comentados, se presentarán en la cuarta sección. 
El nivel relevante es el concepto de seguridad humana como un conjunto de valores, criterios y objetivos. En este punto son importantes tres cuestiones convencionales, a partir de lo que O’Brien y Leichenko (2007) denominan la dimensión de equidad en la perspectiva de la seguridad humana. Primera: ‘̇la seguridad de quién? La respuesta es: la de cada persona. Segunda: żseguridad de quée Respuesta: necesidades, derechos básicos y dignidad. Tercera: ̇̇seguridad de acuerdo con el criterio de quién? La respuesta a la tercera pregunta afecta a todas las que competen el análisis de la seguridad humana. Los criterios significativos provienen de los propios agentes y de los «expertos».

Existen numerosos estudios del (déficit de) acceso a las necesidades y los derechos básicos de los migrantes, así como la dignidad; diversos estudios también dan cuenta de otras personas afectadas por la migración. Aquellos enmarcados en la teoría del desarrollo humano, al igual que el enfoque de seguridad humana, desarrollan evaluaciones multidimensionales interpersonalmente desagregadas (por ejemplo León-Ross et al., 2013 y las fuentes mencionadas en la nota a pie 1). La concentración en las personas antes que el énfasis nacional o regional para la descripción y la explicación es un rasgo compartido con los estudios migratorios transnacionales. Por lo habitual, los estudios de seguridad humana implican algo adicional y exponen un elemento clave que originalmente corresponde a la teoría transnacional y que en ocasiones ha sido relegado. De modo semejante a los enfoques de desarrollo humano y de derechos humanos, se distingue por el respeto normativo y la atención a todas las personas, en cualquier lugar.?

\section{La combinación de la centralidad de la persona y la perspectiva global}

La centralidad de la persona en la ética de la seguridad humana no es solamente para el interior de una nación, sino que es global y se combina en la descripción y la explicación. Tal combinación es más que una simple coincidencia. El

${ }^{7}$ Esta característica se ha hecho menos evidente en los informes de desarrollo humano realizados a nivel nacional y mediante el auspicio del Estado nación. 
compromiso ético global conlleva al interés y la atención de todas las personas, entre fronteras nacionales. Dicha atención promueve el aprendizaje acerca de la gente y de las interconexiones entre fronteras que son fuentes de cambio, oportunidad y vulnerabilidad. A su vez, este aprendizaje fortalece y mejora el compromiso de inclusión normativa.

En cambio, la falta de conocimiento, interés y atención con respecto de la gente en cualquier otro lugar se refuerza de forma mutua. Los países de la Unión Europea han agotado las zonas pesqueras de las costas de África, han hecho que sea más difícil para los campesinos africanos competir en los mercados de ambos continentes, han contribuido sustancialmente al cambio climático que afecta a África y han vendido activamente armas a compradores africanos para luego mostrar consternación e incomprensión cuando aparecen los migrantes africanos en las fronteras europeas (Kaye, 2010; Gasper y Truong, 2014). Ellos buscan limitar la inmigración a la gente con altas capacidades o a las contrataciones temporales cuidadosamente controladas que dejan la reproducción de los migrantes en la niñez o en edades avanzadas en los países de origen. La agenda analítica del enfoque de seguridad humana para la migración incluye la exploración de la inseguridad percibida por las poblaciones europeas y aquellas en otros países ricos.

Aunque los empleadores y los políticos de los países ricos sigan explotando y culpando a los inmigrantes, ellos no dejarán de llegar, dadas las condiciones tan difíciles en sus países de origen y las enormes disparidades globales. Los ricos adoptan la explicación nacionalista, que explica las situaciones en los países de origen sólo en términos de las fallas al interior de las fronteras de cada país, del mismo modo que el preeminente y moderno filósofo social americano John Rawls en su notable obra The Law of Peoples. Mientras que el capitalismo no respeta intrínsecamente las fronteras, establece una alianza con las políticas nacionalistas para otorgar derechos diferenciados que permiten a las empresas conseguir trabajo migrante muy barato. La exclusión legal de los migrantes no perjudica la oferta esperada de trabajo barato; migrantes clandestinos sin derechos o «irregulares» se hacen más baratos aún. El trabajo de la mujer es muchas veces más explotable, considerando que debido a que las mujeres muestran mayor apego a sus familias son capaces de soportar aún más por su propio bien. 
A nivel internacional, las naciones orientadas a favorecer a sus empresas logran acuerdos financieros ventajosos al lidiar con gobiernos e individuos.

Un rasgo característico no-esencial pero importante de la teoría de la seguridad humana se refiere a una advertencia. El principio de la seguridad común (compartida) plantea que la seguridad sostenida de una parte no puede ser posible sobre la base de la inseguridad sostenida de las partes con las que interacciona (Lester, 2010; Mushakoji, 2011). Por ejemplo, Harada (2011) sostiene que el fracaso de Japón para asegurar la inclusión educativa de los hijos de los migrantes ha generado una clase socialmente marginada y pobremente educada destinada a trabajar en la «economía negra» y a activar numerosas consecuencias no deseadas y no previstas para toda la sociedad. Este tipo de inseguridades y sus efectos son evaluados en la investigación sobre seguridad humana, pero por lo común se mantienen fuera del ámbito de interés de las perspectivas del nacionalismo y del capitalismo. La sociedad japonesa no ha internalizado el principio de la seguridad común que sus líderes han querido articular en el ámbito internacional.

\section{Integración de un conjunto de temas en los estudios migratorios relevantes para una mejor descripción y explicación}

Esta sección presenta algunas contribuciones en los estudios migratorios ya sugeridas del uso de un enfoque de seguridad humana, tal como se anunció en la introducción. Cada una de las contribuciones también se encuentra en otras líneas de análisis. Argumentaremos que el análisis de la seguridad humana genera todas las contribuciones de manera conjunta de un modo útil y coherente, $\mathrm{y}$ a veces añade comprensiones especiales.

\section{Observación holística de vidas reales}

El análisis de la seguridad humana observa las intersecciones entre desposesión y vulnerabilidad. Va más allá de la concentración no sólo en la creación y 
expansión de las capacidades para contrarrestar la desposesión, lo cual es típico de algunos análisis de desarrollo humano. El enfoque de la seguridad humana añade el énfasis en vulnerabilidades, riesgos y fuerzas disruptivas y de destrucción (Gasper y Gómez, 2014).

Adicionalmente, el estudio de las amenazas se vincula a la segunda dimensión destacada por O’Brien y Leichenko. Además de la dimensión de equidad en el discurso de la seguridad humana, existe una dimensión de conectividad y un importante énfasis en sistemas interconectados que pueden generar amenazas y fragilidad y también oportunidades que a veces se manifiestan de maneras sorprendentes. El valor agregado del análisis de la seguridad humana proviene en particular de la observación de las intersecciones de diferentes factores y de su significancia conjunta, en vez de mirar solamente de arriba

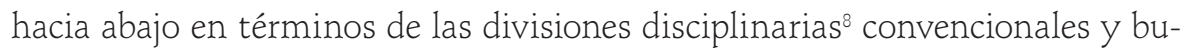
rocráticas. De forma similar, «el sistema de codificación [legal] de razones únicas para el movimiento (negocios, turismo, empleo, educación, solicitud de asilo o reunificación familiar) [subestima] las realidades sociológicas que involucran motivos mixtos y relaciones humanas que evolucionan dentro y entre las fronteras» (Truong y Gasper, 2011: 3). Las vidas de los migrantes evolucionan de maneras imprevistas en tanto se suceden crisis económicas globales, nacionales, familiares o personales y que los problemas de salud y las relaciones emocionales vienen y van, los niños nacen y los mayores mueren. Para ilustrar esas intersecciones de eventos y la fluidez de los motivos y de las categorizaciones, muchas de las mujeres migrantes implicadas en el trabajo sexual ilegal lo han tomado cuando, luego de un periodo de situación legal, ellas no pueden encontrar un trabajo y todavía tienen deudas y deben encontrar una nueva forma de vida (se pueden ver casos en Truong y Gasper, 2011; especialmente en Kojima, 2011).

Las vidas de los migrantes —incluyendo sus identidades, roles, conciencia y oportunidades - cobran sentido al igual que las vidas de todos, en la inter-

${ }^{8}$ Es mejor que usar únicamente los términos de la exageradamente simple lista de cotejo del Informe de Desarrollo Humano de 1994 que difundió el enfoque de la seguridad humana: "seguridad económica», "seguridad personal», "seguridad de la salud», "seguridad alimentaria», "seguridad política», "seguridad comunitaria», "seguridad medioambiental» (véase Gasper y Gómez, 2015). 
sección de múltiples fuerzas: económicas, «culturales», psicológicas, biológicas, legales y burocráticas. Cuando León-Ross et al. (2013) evaluaron el impacto que sobre los migrantes latinos tuvo la crisis económica que comenzó en 2008 en los Estados Unidos de América, examinaron la integralidad de la vida de los migrantes e inesperadamente encontraron que las mujeres migrantes en el ámbito de su estudio, por suerte, pudieron sobrevivir (en muchos sentidos) mejor que los hombres. Los tipos de autoempleo a los cuales ellas podían optar, dadas las restricciones de género, eran menos intensivos en capital y por tanto fue más fácil acceder a éstos que a aquéllos prescritos para los hombres. Asimismo, para las mujeres «era menos probable tener un cónyuge dependiente [en el país de origen] y normalmente compartían con otros hermanos la responsabilidad de atender a sus padres. Por tanto, la presión social para enviar remesas era menor en el caso de las mujeres que en el caso de los hombres» (León-Ross et al., 2013: 209).

Para analizar la realidad de la vida humana en ese contexto, el estudio de las historias de vida de las personas es una manera lógica de explorar la complejidad y las interconexiones. El pedir a la gente que hable acerca de sus historias de vida es un método de investigación usual que se aplica ampliamente en la investigación en el área de la seguridad humana. El libro de Hsiao-Hung Pai Scattered Sand ${ }^{9}$ usa dicho método y reporta las múltiples dimensiones de pobreza en lo que probablemente sea la más grande migración al interior y exterior de China desde los años de 1980. Cada una de las historias de los migrantes muestra la búsqueda de mejoramiento, la lucha contra la adversidad, pero se hallan sujetas a fuerzas mucho mayores de poder económico, estatal y de clase. Los migrantes con escasas capacidades en China tienen pocos o ningún derecho. Sus historias de vida a veces podrían ser vistas como un experimento de Zimbardo que no tiene fin. ${ }^{10}$ Carecen de contratos, a menudo se les paga con meses de retraso y algunas veces no se les paga nada, están sujetos a

\footnotetext{
${ }^{9}$ Nota del traductor: se mantiene el título del libro en su versión original, el cual podría traducirse como «Arena dispersa».

${ }^{10}$ La simulación de una prisión en la Universidad de Stanford realizada por Philip Zimbardo en 1971 tuvo que ser cancelada después de tan sólo seis días debido a la creciente crueldad y el sufrimiento entre los «actores», que eran los estudiantes participantes.
} 
descuentos unilaterales, son obligados a trabajar horas extras de modo ilimitado y es habitual que no se les pague por ello, pueden ser despedidos o se les puede reducir sus horas de trabajo en cualquier momento, tal como ha sucedido decenas de millones de veces luego de la crisis de 2008. Uno de los migrantes menciona que al estar sometidos al irrestricto y concertado poder de las empresas, de los partidos políticos, del Estado y de las fuerzas del crimen, ellos son como los millares de granos de arena en la playa. En efecto: el libro de Pai concluye en una playa, los pantanos de la bahía de Morecambe en el noroeste de Inglaterra, en el evento que despertó la atención de una asombrada audiencia británica hacia la actual emigración global china: 23 trabajadores ilegales chinos se ahogaron mientras trabajaban durante la noche en febrero de 2004, vencidos por la llegada de la marea. Dispuestos a dejar las dificultades de la China rural y de sus pequeños pueblos y a lograr algo para sus familias, endeudados enormemente después de pagar a los traficantes, ansiaban tomar cualquier trabajo. Sus jefes británicos y chinos no les advirtieron al respecto ni los equiparon para evitar los peligros. Sabiendo poco o nada de inglés no pudieron llamar por teléfono para pedir ayuda, solamente pudieron comunicarse con sus familias en China para despedirse. Pai habló por muchos años con los sobrevivientes y con las familias de quienes murieron, incluso ayudó a organizar una campaña de recolección de fondos a fin de pagar las deudas de las familias (véase también Pai, 2008; Gasper y Truong, 2010b).

\section{Identificación de discriminación estructural y exclusión}

Los ejemplos de investigaciones que hemos mencionado combinan el análisis estructural con la observación de los detalles de las situaciones individuales de las personas, incluyendo la manera en que ellos las perciben. Este tipo de trabajo brinda mayores aportes a los estudios sobre derechos humanos, lo que permite identificar el daño causado a los individuos por diversos agentes; no obstante, lo anterior puede no ser útil en la identificción de las barreras estructurales que enfrentan los migrantes, lo que comprende las estructuras de poder político y económico y las limitaciones culturales que básicamente influyen 
su seguridad humana. Por ejemplo, las prácticas discriminatorias para la contratación, el despido y la caracterización étnica que hace la policía, dañan a los migrantes de modo desproporcionado. En general, los migrantes se mueven en contextos sociales estructurados por fuerzas económicas, por la autoridad del sistema de Estados nación, por las identidades adscritas administrativamente, identidades étnicas, culturales y de género y otras relaciones de poder. Los sistemas capitalistas de mercado — en sus formas legal, ilegal y casi legalinducen, conducen y restringen la movilidad de diversas maneras; los sistemas de Estados nación establecen derechos de jure o de facto y derechos para los migrantes; y las relaciones de poder de género y las jerarquías étnicas también afectan grandes grupos de migrantes. En conjunto, estos diversos sistemas de poder crean regímenes migratorios híbridos que usan y explotan trabajo migrante (Gasper y Truong, 2014: 22).

Pogge (2005) y Bagchi $(2008,2011)$ advierten que uno de los elementos centrales en las estructuras de poder económico son los cuantiosos flujos de capital —legales, cuasilegales y a menudo descaradamente ilegales - que van desde países de ingresos bajos y medios hacia los países ricos y que exceden con mucho cualquier ayuda internacional (véase también Ajayi y Ndikumana, 2014). El sexto reporte anual de Global Financial Integrity, Illicit Financial Flows from the Developing World: 2003-2012,11 estimó que el flujo ilícito que salió de las economías en desarrollo y emergentes fue de 6.6 trillones ${ }^{12}$ de dólares americanos desde el 2003 hasta el 2012.13 El flujo del capital se suma a las necesidades y deseos de emigrar, pero estas remesas en reversa logran muy poca atención en los estudios migratorios. Los principales países que reciben fondos ilegales como Estados Unidos de América, a pesar de sus propias historias de emigración a gran escala o inmigración en contra de la voluntad de los habitantes originarios, han estado más involucrados en la prevención de la

${ }^{11}$ Nota del traductor: se mantienen en su versión original tanto el título del documento como el nombre de la institución referida. En cualquier caso, la traducción sugerida es: Integridad Financiera Global, Flujos financieros ilícitos del mundo en desarrollo: 2003-2012.

${ }^{12}$ Nota del traductor: se conserva la denominación original «trillones», pero es necesario advertir que dicha denominación corresponde en español con el término «billones» (millones de millones).

${ }^{13}$ http://www.gfintegrity.org/report/2014-global-report-illicit-financial-flows-from-developingcountries-2003-2012/ (revisado el 22 de agosto de 2015). 
inmigración de gente de países pobres que en la prevención de flujos financieros ilícitos. ${ }^{14}$

El análisis de la seguridad humana considera que las vulnerabilidades se configuran al interior de esos contextos estructurales y examina si «la violación de los derechos tiene lugar como parte de un patrón sistemático [...] de discriminación y vulnerabilidad estructural» (Rubio-Marin y Estrada-Tanck, 2013: 253; aplicado al caso de los migrantes, véase Oberoi, 2010; Estrada-Tanck, 2013, 2015). Tales estudios, ya que prestan bastante atención a las subjetividades, nos ayudan a tratar totalmente en serio los derechos humanos y las violaciones a los derechos humanos, a entenderlos mejor y a identificar las reformas estructurales que se requieren. Cuando el análisis de los derechos humanos ha sido o puede ser ampliado para hacer lo mismo, entonces las dos corrientes se fusionan.

Una representación psicológica más completa de la gente: sobre las esperanzas y los miedos, pertenencia y el llegar a ser

Sabemos que el cálculo económico convencional no basta para explicar los movimientos migratorios. Numerosas personas, incluyendo todas las clases sociales y todas las latitudes, tratarían de migrar si el cálculo del beneficio económico fuera el único o el criterio de decisión predominante. De la misma manera, los países ricos que no tuvieran poblaciones que envejecieran con rapidez o se hallasen en declive tal vez recibirían cálidamente los flujos de inmigrantes. El análisis económico excluye mucho de lo que a la gente le importa: familiaridad con el lugar y tradición, cercanía con las personas queridas, sentimientos de pertenencia y más; así como sus miedos, sospechas e incertidumbres, sus representaciones idealizadas con frecuencia y sus antagonismos con respecto de otros grupos.

Al respecto, los modelos de «aspiraciones» para migrar, y más generalmente de ambiciones, tienen que considerar una pluralidad de posibles motivos que de modo reiterativo incluyen el intento de satisfacer expectativas sociales

${ }^{14}$ El estado de Florida es el principal destino de la fuga de capitales de América Latina (Barry, 2014). 
cambiantes y la percepción de obligaciones para con la familia, o la búsqueda de seguridad física, nuevos desafíos o afiliación o libertad religiosa, política, cultural o sexual..$^{15}$ Sharma (2008) reporta que los jóvenes nepaleses eligen la migración internacional no solamente con la expectativa de mayores ingresos y seguridad sino como un medio para la madurez, el aprendizaje y la posición social. Huijsmans (2014) considera un comportamiento similar entre jóvenes migrantes de Laos a Tailandia.

La teoría de las capacidades aporta algún refinamiento al modelo de elección de la teoría económica del consumidor, pero aún no ha llegado tan lejos. En comparación con la perspectiva convencional de la economía del bienestar, ésta aporta una evaluación multidimensional, desagregada interpersonalmente y reflexiva. No obstante, cuando se discute si la migración y la movilidad son deseables como fines o sólo como medios (por ejemplo De Haas, 2014), permanece dentro de las categorías de la teoría del consumo. No siempre hará justicia a etapas cruciales en la vida que determinan el tipo de persona que alguien llegará a ser. De Haas retoma el asunto al final de su artículo: «żEn qué medida podemos ciertamente separar aspiraciones migratorias intrínsecas de las instrumentales ya que a menudo parecen fusionadas en la práctica?» (2014: 34). También enfatiza que «a menudo existe un conflicto entre el deseo de ser miembro de un grupo social por razones psicológicas y sociales de seguridad y la motivación personal hacia la autonomía. Esto muestra la importancia de desarrollar herramientas conceptuales que nos puedan ayudar a desarrollar comprensiones más específicas de la interacción entre estructura y agencia en la acción social» (2014: 34).

El enfoque de la seguridad humana para el estudio de la migración posee herramientas y aproximaciones que ofrecer relativas a las «razones psicológicas y de seguridad social», desde diversas fuentes, incluyendo consideración de la identidad, cuidados, miedos, reconocimiento y dignidad y no únicamente el riesgo compartido (Balsera, 2014; Gasper y Truong, 2010; Grønseth, 2013; Tripp et al., 2013). Una visión del ser humano que de forma impresionante enfatiza la elección y la capacidad de autonomía desconoce muchas otras cosas de

${ }_{15}$ Por ejemplo, la investigación IMI-Oxford sobre los determinantes de la migración internacional: http://www.imi.ox.ac.uk/projects/3 
relevancia capital, tanto para una explicación adecuada como para la orientación ética; es decir «relaciones de cuidado y reciprocidad en mutuo reconocimiento y respeto. De esto [el desconocimiento] no puede esperarse la seguridad humana como resultado» (Truong y Gasper, 2011: 11) ni tampoco que se la explique adecuadamente. Así, el enfoque de la seguridad humana enriquece la investigación acerca del desarrollo humano.

Por otro lado, el tema de la vulnerabilidad forma parte de un contexto más amplio de personas que enfatiza más que en capacidad y elección racional y más que en el estatus de poseedores de derechos. Las cuestiones de seguridad, inseguridad y amenaza se conectan a emociones y miedos y a percepciones de los peligros; sus conexiones son en parte inevitablemente subjetivas y tienden a sesgarse. El enfoque de la seguridad humana ha llegado a considerar y evaluar como elementos centrales tales percepciones de seguridad e inseguridad y sus determinantes, y cómo la seguridad y la agencia interactúan. La psicología de la seguridad e inseguridad humana es crucial e incluye el plano de oportunidades percibidas, peligros e identidad (Gasper y Truong, 2010a). Al concentrarse en cómo piensan diferentes actores acerca de la migración y la integración, el enfoque de la seguridad humana ofrece considerables aportes en los procesos de toma de decisión que involucran y equilibran la seguridad material y emocional.

Promoción de la reflexión sobre planos y categorías:

identidad, comunidad, integración

La reflexión a partir de un enfoque en las personas concerniente a las características y las causas de la vulnerabilidad permite reflejar el asunto en el ámbito, el enfoque y las categorías en las discusiones convencionales y en los contextos de diseño de políticas. Ayuda a reconocer puntos ciegos y a identificar quien se halla categóricamente excluido y ha quedado vulnerable. Por tanto, la vulnerabilidad surge a través de un sistema institucionalizado de percepción que refleja y contribuye a los sistemas de poder. Por ejemplo, el trabajo doméstico y los trabajadores domésticos están en su mayoría excluidos de las categorizaciones laborales usadas por los estados: el trabajo doméstico no es visto como «trabajo 
de verdad». Esos trabajadores son en su gran mayoría mujeres, usualmente de otros países. La reproducción social de los países ricos y de los ricos en los países de ingreso medio y bajo — además de la balanza de pagos de países muy grandes, inclusive como Indonesia y Filipinas - depende de esas mujeres trabajadoras cuya propia seguridad humana y su reproducción personal y familiar con frecuencia se encuentra bajo una enorme presión (Truong, Gasper y Handmaker, 2014; varios capítulos en Truong et al., 2014).

Es posible mencionar como un segundo ejemplo que mientras los estudios migratorios se han orientado tradicionalmente hacia la migración permanente, han surgido en una escala sin precedentes formas de migración temporal, circular y transitoria que por lo usual involucran mujeres y niños con patrones particulares de inseguridad. Los lenguajes de política existentes para mujeres y niños (tal como el enfoque de derechos de grupo) se ajustan mejor a las cuestiones de integración de migrantes ya establecidos que a las situaciones de las comunidades de migrantes circulares, temporales y transitorios (Gasper y Truong, 2014). Comenzar con las historias de vida de la gente real antes que con categorías supuestas generalizadas puede revelar sus puntos ciegos.

Eriksen et al. (2010) advierten que no se debería analizar solamente a la población vulnerable, a los migrantes o a las inseguridades materiales. El enfoque centrado en la persona debe ser usado con amplitud, para considerar a todos los que están involucrados y son afectados. El enfoque de seguridad humana puede llamar la atención respecto del impacto de la migración transfronteriza sobre la naturaleza de la comunidad y las identidades políticas y la evolución del «yo» y del «nosotros», lo que en la teoría de las capacidades «tienen (o buscan) una razón para valer» supuestos bienes o derechos y cuyas necesidades básicas deberían asegurarse. Esto permite considerar las (in)seguridades materiales y emocionales y las cambiantes identidades de los residentes y de las nuevas generaciones (Eriksen et al., 2010; Gasper y Truong, 2010a; Mushakoji, 2011; Burgess et al., 2007). La confusa mezcla de respuestas a la actual crisis migratoria de Europa — desde el cierre de la frontera hasta los esfuerzos de categorizar e identificar a los migrantes sobre la base de un supuesto merecimiento hasta la asistencia humanitaria en favor de los migrantes cuyas vidas se consideran en riesgo - ilustra la conflictiva evolución de la identidad europea 
y las diferentes elecciones acerca de cuáles (in)seguridades se deben atender y a quiénes pertenecen.

Pueden existir profundas tensiones. Por un lado están las necesidades de reproducción social de los países de inmigración (en particular, relacionadas al trabajo en la atención de la salud, trabajo doméstico y otras áreas) y la seguridad de las condiciones de vida y las necesidades culturales percibidas de los inmigrantes; todo eso frente a la «seguridad comunitaria» percibida de los residentes ya establecidos. Shani recuerda que debemos ver «la importancia de la cultura no como vínculos primordiales pero como marcos de sentido a través de los cuales las personas pueden lograr dignidad» (2015: 16). Desafortunadamente, las culturas nacionales y las culturas de grupo y subculturas a veces se apoyan en marcos de sentido que denigran a los foráneos no menos que los migrantes.

Una gran parte de la literatura relativa a integración y transnacionalismo ha tratado ambos conceptos como opuestos y ligados a tradiciones en competencia. Supuestamente, los migrantes migran de una «comunidad» a otra. La integración equivale a una adaptación a las estructuras de la sociedad receptora y a la adopción de normas y valores existentes; en tanto que las conexiones transnacionales son vistas como una señal de no-adaptación y no-integración. Por el contrario, el análisis enfocado en las personas hace posible evaluar los significados que han sido construidos en cuanto a esas estructuras y esas conexiones, tanto para migrantes como para no-migrantes, para los que diseñan las políticas y para los académicos y sus interpretaciones y re-interpretaciones.

Una vez que se reconoce que las categorías del Estado son simplistas se comienza a explorar acerca de cómo están construidas y cómo condicionan la vida de la gente. Se aprecian las categorías que usan los migrantes y varios grupos en la sociedad de destino y en la sociedad de origen, de manera que se puede reflexionar sobre cómo, en tanto investigadores, también adoptamos, construimos y usamos categorías. Un punto de partida para dicho análisis requiere considerar la forma en que las personas que se mueven construyen sus sentidos de identidad y pertenencia de modo tal que eluden las categorías del Estado, pues no se ven a sí mismos como únicamente A o únicamente $\mathrm{B}$, o un poco de A y un poco de B, pero tal vez se ven como algo nuevo, lo cual podría comprender diversos aspectos. Este enfoque nos conduce más allá de la noción de la «integración» del migrante que 
significa que los migrantes se acomodan a estructuras sociales preexistentes. La exploración de cómo la gente se involucra en la integración y el transnacionalismo muestra que la gente participa en múltiples sistemas sociales; asimismo, revela cómo la integración y el transnacionalismo coexisten e interactúan como resultado de procesos deliberadamente realizados que toman en cuenta la seguridad material y la seguridad emocional (Sinatti y Gasper, 2015). En este caso el enfoque de la seguridad humana utiliza el trabajo disponible en los estudios de migración transnacional por medio de las preguntas que se plantean, aporta quizá a la comprensión de la problemática.

\section{Vinculación de la reflexión acerca del nacionalismo}

La evaluación del nacionalismo metodológico permite reflexionar sobre el nacionalismo político y cultural. Al considerar las complejidades y vulnerabilidades en la vida real de las personas uno se hace más consciente de la construcción social en cada país acerca de una comunidad imaginada, el universo mental de ons land (para tomar el ejemplo holandés «nuestra tierra», una expresión de uso cotidiano) y de su correspondiente devoción. El nacionalismo es en parte una respuesta al hecho de vivir en sociedades modernas con sus tensiones y presiones. Ofrece a individuos desarraigados y desarraigables un hogar, la base de la identidad y cierta percepción de seguridad y familiaridad. Por tanto, aunque el capitalismo y el nacionalismo son principios diferentes en lo fundamental, por lo general se acomodan juntos.

Usualmente, la identidad nacional en una "comunidad imaginaria» se construye en contraste a los "otros imaginarios»: imágenes estereotipadas y homogeneizadas que se construyen respecto de los otros. La búsqueda de seguridad a través de la formación de una comunidad imaginaria excluyente genera de ese modo inseguridad, puesto que amenaza a otros y provoca reacciones. Además, el nacionalismo erige un orden moral con estándares completamente distintos para el interior y el exterior. Al interior de la comunidad nacional se debn aceptar algunos elementos de igualdad y fraternidad; en el exterior, se considera que es viable aprovecharse de otros de múltiples maneras. Por ejemplo, uno podría 
estar obligado a pagar un salario decente internamente, pero no sólo se le permite sino que se le alienta a explotar a aquellos que están fuera; antes, esto se hacía abiertamente mientras que ahora tiene lugar detrás del velo de los mercados. Cuanto más numerosos y exigentes son los principios de las obligaciones internas, es mayor la tensión ética que surge por el contraste en las orientaciones relacionadas con los otros no-nacionales. Dichas tensiones éticas se vuelven en particular intensas y pueden derivar en tensiones políticas vinculadas a los migrantes residentes, sobre cuyo trabajo depende un país y a quienes no se otorga la membresía legal total o el respeto igualitario. El sentimiento de seguridad de los ciudadanos se ve comprometido por el sistema paralelo en el cual los países toleran de facto grandes volúmenes de migrantes irregulares quienes ofrecen trabajo barato en sectores abandonados por los ciudadanos. Al mismo tiempo la migración crea un sistema global en el que la gente forma parte, de forma simultánea y creciente, de numerosas comunidades moralmente constituidas, no territoriales y que se traslapan (Erskine, 2000; Gasper, 2005). Una pregunta importante sería: ¿̇En qué medida esta tendencia contrarresta las respuestas nacionalistas a (y la creación de) tensiones y presiones? (Gasper, 2011).

\section{Sugerencias para el análisis de la política migratoria y para la gobernanza}

[El impacto de] la falta de comprensión de la gente simple y la escasez de luces que daría el conocimiento de ellos, puede ser rastreado no solamente en el desajuste social y político de los inmigrantes en los centros municipales, también se percibe en los denominados «asuntos prácticos» de escala nacional.

Addams, 1907: 65, citado por Malavisi, 2015.

Hemos destacado el hecho de que el enfoque de la seguridad humana concentra la evaluación en las vidas de todas las personas y que esto incluye la preocupación por las dimensiones de sentido y por la seguridad emocional y existencial de la gente que se refleja en el discurso de la «libertad para vivir con dignidad». En 
términos generales, el enfoque debería ayudar a reorientar el análisis de política hacia la atención en los impactos y significados en las vidas de tipos específicos de personas. ¿Qué y cómo es que se aporta al análisis de política? En la literatura respectiva se han sugerido algunos principios generales para el análisis político orientado por el enfoque de la seguridad humana y también existen varios con referencia específica a la migración internacional. Tales principios se sujetan a las advertencias contra la securitización y sobregeneralización. Consecuentemente, un principio general clave que es necesario destacar es el de la provisión de espacio para la participación de los migrantes y la vivencia de sus experiencias.

\section{Cuestiones de politica orientadas por el enfoque de la seguridad humana}

La Comisión de Seguridad Humana (2003) desarrolló un conjunto de diversos elementos característicos de una perspectiva de seguridad humana en el análisis de política, los cuales mostraban un enfoque no solamente orientado a las personas sino centrado en ellas, destacando el empoderamiento y no sólo la protección. Se basó en el trabajo del corresponsable de la comisión Amartya Sen, en libros sobre la teoría de las titularidades y estudios del hambre, muchos de los cuales fueron escritos por Jean Drèze (véase en especial Drèze y Sen, 1989). Argumentaciones equivalentes existen a partir de la Unidad de Seguridad Humana de las Naciones Unidas y del PNUD (por ejemplo, Gómez y Gasper, 2013). Entre esos elementos se mencionan los siguientes:

- Análisis de las condiciones de vida, de las titularidades y las vulnerabilidades de las personas, el cual puede identificar los riesgos que enfrentan y las opciones para empoderarles. Se logra una mejor identificación del riesgo por medio de una apertura a unas fuentes más amplias de información y a múltiples perspectivas, y a través de la desagregación social y espacial en la investigación y en las estadísticas.

- El seguro vía el empoderamiento y la prevención en numerosas ocasiones es mucho menos costoso y más efectivo que mediante la reparación después del desastre. 
- Usualmente, el empoderamiento requiere la institucionalización de una lógica basada en los derechos.

- Debido a las interconexiones intersectoriales - tales como los nexos entre migración, economía, clima, conflicto, etcétera - y a causa de las implicaciones en las prioridades intersectoriales y al costo efectivo de las opciones, se requiere extraer el diseño de política fuera de los ámbitos sectoriales, al menos con cierta periodicidad. Deberíamos alternar entre concentrarnos en áreas prioritarias y reconsiderar periódicamente cuáles son las áreas prioritarias (Gómez y Gasper, 2013).

- Tomar en cuenta las interconexiones e interrelaciones también sirve de apoyo al principio de la seguridad humana común.

Una de las implicaciones fundamentales de política con relación a la migración es la prioridad de esquemas portables de protección social. Los migrantes se desplazan, pero a menudo sus derechos - de pensiones, seguridad en el trabajo y otros derechos sociales acumulados - no pueden trasladarse y esto sucede en específico en el caso de los migrantes temporales, circulares y transitorios. Comúnmente la migración no es un proceso de transferencia único y definitivo, más bien es un proceso fluctuante, riesgoso, parcial y experimental en el largo plazo. Un régimen de protección social debe tener el mismo alcance que el sistema económico contra y dentro del cual pretende proteger (Gasper y Truong, 2014). Por ejemplo, en ese sentido, China, tendría que cambiar su sistema de protección social basado en la localización y convertirse en un sistema de escala nacional, de acuerdo con Zhu y Lin (2014). Principios similares aplican globalmente (Taha et al., 2015).

Cuestiones de seguridad humana común, dignidad y respeto mutuo

El principio de la seguridad común — que la seguridad para uno a largo plazo requiere seguridad para todos - ha sido promovido bajo esta denominación por lo menos desde la Comisión Palme en 1982. Aunque originalmente fue formulado 
con respecto a las relaciones entre Estados, también ha sido articulado al nivel de personas; así, Kinhide Mushakoji (2011) escribe acerca de la «seguridad humana común». Mushakoji, además, ha aplicado el tema en particular a la seguridad y la reproducción de la identidad. La noción Westphaliana de una sola identidad en un Estado nación homogéneo ya es obsoleta, y los Estados deben respetar la reproducción de la identidad y garantizar la seguridad de cada comunidad de identidad en su interior. La marginalización de cualquiera de esas comunidades resultaría en última instancia en el perjuicio de todas, argumenta Mushakoji, mientras que las comunidades de identidad dual pueden llegar a ser activos nacionales, puentes hacia un mundo más amplio.

Una perspectiva global no debe utilizar la clasificación dentro/fuera como postura ética aplicada por el nacionalismo; al contrario, debe usar el principio de todos-afectados, articulado por Nancy Fraser (2008) y antes de ella por Onora O'Neill (1996) y otros. Uno es responsable por todos los que son afectados por sus acciones, incluyendo aquellos que provienen de otros países. De manera similar, el principio de todos-dependientes requiere que todos los que dependen de una estructura de gobierno, incluidos los migrantes externos dentro de un país, deben ser tratados como dependientes de la justicia en esa estructura (Gasper y Truong, 2014).

La seguridad percibida de los ciudadanos es discutiblemente promovida por la construcción del compromiso del inmigrante a través de la provisión de medios legales para el ingreso y la legalización. Todo ello es mejor que si se usan barreras complejas para el ingreso combinadas con una cierta tolerancia de facto al trabajo requerido; dicho ingreso ocurre a gran escala pero se mantiene en situación irregular. Diversos paralelismos existen entre el apartheid sudafricano en el siglo XX y los sistemas que muchos países ricos han establecido en el siglo XXI (véase, para el caso de Japón, Mine, 2011). Grupos de poder en Sudáfrica intentaron sin éxito fortalecer su propia seguridad dejando a otros sin ella. Para trascender el apartheid fue necesario comprender empáticamente las lesiones y los miedos de todos, incluyendo sus inseguridades psicológicas y económicas, y el mismo principio se aplica en todos los casos.

Así, la base para la adopción de los principios de seguridad común, todosafectados y todos-dependientes, es el reconocimiento respetuoso de otras 
personas. La idea de la seguridad humana, siguiendo la retórica fundacional de las Naciones Unidas, destaca la idea de la dignidad humana - el principio del valor humano que deriva en el derecho a vivir una vida con dignidad. Se trata de ideas cada vez más importantes en la jurisprudencia (McCrudden, 2003; Düvell et al., 2013; Murphy, 2015).

El enfoque de la seguridad humana considera que el respeto activo hacia otras personas se estimula al tener una comprensión informada acerca de los contenidos de su vidas (Gasper, 2011). A diferencia de una gran parte de la literatura en relaciones internacionales, es necesario observar en detalle la vida de los migrantes. El trabajo de Grønseth Being human, being migrant't6 (2013) no enfatiza en la manera en que los migrantes son diferentes sino en la forma en que son arquetípicamente humanos, humanos modernos, agentes que se mueven buscando expresarse a cabalidad y buscando un reconocimiento total, que viven vidas de cambio en las interfaces de diferentes mundos de vida; son quienes deben innovar frente a tensiones y barreras. La comprensión informada indispensable comprende el registro histórico global de desposesión, dominación y discriminación durante los últimos cinco siglos. Bagchi (2008, 2011) y otros cuestionan a las naciones que por la fuerza colonizaron su actual territorio u otros países y que ahora aplican estrictos estándares de exclusión.

\section{Peligros: securitización y sobregeneralización}

Los peligros de sobregeneralización existen tanto en la prescripción como en la explicación. El enfoque de seguridad humana antes descrito intenta evitar la sobregeneralización concentrarse en las particularidades en cada caso: en el nivel de las ideas (incluyendo las ideas acerca de las naciones, el género, la raza, el bienestar y otras), el nivel de las estructuras de poder políticas y económicas, las instituciones específicas y las redes involucradas en los procesos de migración

${ }^{16}$ Nota del traductor: se conserva el título de la referida obra tal como aparece en la versión original. Su versión en español podría ser Ser humano, ser migrante. 
y en la compleja interacción de todos los factores en la vida de las personas (Truong y Gasper, 2011; Gasper y Truong, 2014).

La retórica de la seguridad humana normalmente es acusada de problemas de securitización, contribuyen a ello poderosos actores que manipulan el lenguaje de la «seguridad» para sus propios objetivos, lo que genera un corto-circuito en la discusión democrática y científica. En realidad, el sentido alrededor del cual se produce la confusión ha existido por milenios y no es provocado ni exacerbado por la perspectiva de la seguridad humana. Más bien es una perspectiva de la vida y los derechos de gente pobre y ordinaria, incluyendo cientos de miles de "personas en movimiento». La securitización es un intento de callar a otros, mientras que el enfoque de la seguridad humana es lo opuesto.

Presentación de voces y experiencias vividas de los migrantes

Las perspectivas de seguridad humana han sido marginales en el análisis de política dominante vinculada con la migración, tal como lo han documentado Edwards y Ferstman (2010). Los migrantes son marginales respecto de los centros de poder que manejan el diseño de políticas y el análisis legal a nivel del gobierno, intergubernamentalmente o por comisión. Por tanto, la Organización Internacional para la Migración mantiene a los migrantes al margen en sus deliberaciones; sus clientes son Estados nación, en especial los Estados que la financian y sus poblaciones domésticas y corporaciones. Oberoi (2010) destaca cómo tienen lugar las reuniones de migración internacional ante la ausencia de una representación migrante oficial. En consecuencia, décadas de reuniones y reportes sobre los derechos de los migrantes han derivado en algo más bien pequeño. Además, si las convenciones generales en torno a derechos humanos fueran tomadas en cuenta con seriedad en lo concerniente a los migrantes, entonces las discusiones de una convención especial para migrantes hubieran sido totalmente innecesarias (Oberoi, 2010; Lester, 2010). Los valores y el pensamiento de la seguridad humana son intentos de humanizar y enmendar los avances del sistema del Estado nación y del capitalismo global a través de una reorientación de la perspectiva, del análisis y de la política y no sólo de la 
ley (CHS, 2003; Gasper y Truong, 2010). El trabajo que está orientado por una perspectiva de seguridad humana ayuda a exponer lo que se mantiene invisible de la migración y fortalece las bases para el reconocimiento ético y político y para la acción informada y efectiva.

La invisibilidad cognitiva de los migrantes es fundamental: su exclusión del campo de visión y de la mesa de diálogo pública, como lo es en el caso de los trabajadores domésticos y muchos migrantes temporales, circulares e irregulares. Ello implica exclusión de la cobertura estadística, exclusión del estatus legal, exclusión de la atención de la política pública y exclusión de la consideración humana. La investigación de la seguridad humana sobre la migración intenta contrarrestar esta exclusión mental, de modo que se logra congregar a investigadores, operadores políticos y activistas de la migración. Sandoval-García (2014) presenta ejemplos de Costa Rica del trabajo cooperativo con el propósito de preparar una sentencia de inconstitucionalidad de la ley de migración presentada a la corte constitucional, para analizar y deconstruir las formas en que los nicaragüenses son descritos en ese país y se discute sobre ellos y para apoyar a las comunidades inmigrantes en sus propias auto-representaciones. La investigación etnográfica y el uso de testimonios directos y las historias de vida son métodos importantes que otorgan voz a los migrantes (véase Pearson y Kusakabe, 2012) y contrarrestan la inadecuada representación de otros o la invisibilidad, que reportan las redes de inseguridad y difunden las luchas de los migrantes.

Los países de inmigración podrían no sentir la necesidad de estudiar las perspectivas de la gente en movimiento, pero la inseguridad que periódicamente se siente relacionada con los inmigrantes podría derivar en medidas desinformadas y de pánico que no podrían identificar ni tomar oportunidades con beneficios multilaterales. Tandian y Bergh (2014) exponen un esquema desastroso dirigido a la promoción de la migración estacional regulada de Senegal a España para trabajo de campo agrícola; empero, este esquema propició exactamente lo opuesto: inmigración «irregular» de largo plazo en los sectores de servicios de cuidado personal y trabajo doméstico. Luego, España y Senegal dialogaron sobre las maneras mediante las cuales se podrían lograr acuerdos mutuamente beneficiosos, con la idea de escuchar y aprender. España necesita varios tipos de trabajadores, en concreto en el trabajo doméstico y el cuidado de los ancianos; 
mientras que muchos migrantes senegaleses están interesados en dividir su tiempo entre los dos países (y eventualmente, volver a Senegal de forma permanente). Sin embargo, el acuerdo requiere que dichos migrantes tengan la confianza de no ser excluidos de España cuando visiten Senegal.

\section{Comparaciones y necesidad de asociaciones}

El enfoque de la seguridad humana es un amplio abordaje y perspectiva, a veces se le llama un leitmotiv o un repertorio de leitmotivs conectados (Werthes y Deniel, 2006; Gasper, 2010; Oberleitner, 2012). Es más que un título evocativo aunque no es un modelo detallado o una teoría; tampoco un conjunto relativamente preciso de normas como las de los derechos humanos internacionales. Otras opciones y otros marcos analíticos pueden asumir en conjunto sus roles, pero su amplia adopción y difusión en la generación pasada indica que el enfoque se constituye en una útil síntesis para varios efectos y que provee más que otras perspectivas más estrechas (Gasper y Gómez, 2014, 2015). En vista del grado de vaguedad en un contexto más amplio, el enfoque de la seguridad humana debe ser aplicado en conjunción con varios enfoques, muchos de ellos más estrechos y más detallados, y no solamente desde un amplio punto de vista antropológico/fenomenológico (Grønseth, 2013). Ya se han mencionado con anterioridad como socios a los enfoques de derechos humanos, capacidades humanas y el estudio del nacionalismo. Ahora se verán con mayor precisión los primeros dos y adicionalmente se abordarán los trabajos que comprenden las condiciones de vida de los migrantes y su bienestar y en especial el estudio de la migración que es sensible al género. En cada caso se sugiere que el enfoque relativamente más estrecho y detallado puede al mismo tiempo aportar y beneficiarse del enfoque de seguridad humana.

Investigación sobre las condiciones de vida y el bienestar de los migrantes

Al igual que la investigación en seguridad humana, la investigación sobre las condiciones de vida es holística, transversal, se concentra en explicaciones 
sistémicas y en el individuo (en la práctica se enfoca en familia/hogar) para la descripción y la evaluación (De Haas, 2010). Ofrece una dimensión esencial para la investigación en seguridad humana. De varias maneras, sin embargo, la investigación de la seguridad humana logra más de lo que se requiere para comprender la vida de los migrantes y los procesos migratorios y sus impactos. Es más amplia en sus alcances y se refiere a la integralidad de la vida de las personas - por ejemplo, con las necesidades de salud sexual y reproductiva de las mujeres migrantes y no únicamente con cuestiones económicas (Truong, Marin y Quesada-Bondad, 2014). Asimismo, presta más atención a la subjetividad y por tanto nos ayuda a comprender mejor las especificidades de los individuos y el cambio social. Cabe resaltar que por la combinación de su enfoque en eventos con el análisis estructural, al estilo de un historiador, el enfoque de la seguridad humana quizá es más dinámico y más abierto a la complejidad y a las divergencias introducidas por contingencias y crisis.

Muchas de las cosas que se logran a través de dicho enfoque se consiguen de igual forma por la investigación sobre el bienestar de los migrantes (véase Wright, 2010, 2011, 2012; Grønseth, 2013). «El concepto de bienestar humano [...] sirve como un paraguas o marco analítico integrador que reúne ideas a través de una serie de disciplinas (economía, psicología, sociología) en un espacio común o marco conceptual, destacando las complejas interacciones que existen entre las dimensiones material, perceptual y relacional» (Wright, 2011: 1459).

La mayor parte de lo que Gasper (2011) presenta como un marco analítico influido por la seguridad humana para evaluar el bienestar del migrante podría presentarse como investigación sobre el bienestar:

[Nosotros] hemos estudiado aspectos característicos de la vida de los migrantes, incluyendo la confrontación de riesgos, migración existencial y migración en la identidad. La migración existencial que produce la migración espacial afecta no solamente a los migrantes espaciales, sino también a las personas que dejan atrás y aquello en el lugar de destino, en ese sentido, todos son migrantes. [También hemos discutido] el patrón común de aparentes incrementos en el bienestar objetivo acompañado por la disminución en el bienestar subjetivo (Gasper, 2011: 270). 
Las dos corrientes de investigación son complementarias y compatibles: atienden a la vez a las dimensiones material y subjetiva y a sus interacciones; se observa la manera en que piensan los migrantes; y no ven a los migrantes solamente desde arriba como unidades de trabajo supuestamente controlables. Ni el enfoque del bienestar ni el de la seguridad humana se sorprenden, por ejemplo, por el fracaso en la reducción del número de migrantes a través de políticas de comando y control, las cuales en numerosas ocasiones han llevado a reducir la predisposición del migrante para volver o visitar su país de origen.

Destaca que la investigación del bienestar tiene más detalle en los elementos y las causas del bienestar o de su ausencia, por ejemplo, sobre cómo las aspiraciones no realizadas afectan o menoscaban el bienestar percibido. La migración emerge a menudo de aspiraciones relativamente elevadas pero por lo general deja a muchos migrantes con calificaciones y experiencias devaluadas y se convierte en una vía de movilidad social descendente (Wright, 2010). En cambio, la investigación de la seguridad humana es más dinámica y explora los eventos que distraen, irrumpen y destruyen el bienestar y también los procesos que lo producen, por lo que es esencial para comprender trayectorias de vida y no solamente tomar instantáneas. Tal como se ha sugerido en la sección previa, el enfoque de la seguridad humana también abre un espacio para pensar categorías y estructuras. Cuando un académico del bienestar y uno de la migración evaluaron en conjunto los impactos de la crisis económica global posterior a 2007 en torno a los migrantes y el bienestar (Wright y Black, 2011) analizaron material diverso sobre impactos materiales, psicológicos y relacionales, pero no exploraron los impactos de categorías socioeconómicas estructurales. Al realizar la comparación con el enfoque del bienestar, los estudios de seguridad humana de la migración muestran una mayor atención a los detalles de las condiciones de vida y aprovisionamiento y hay mayor orientación de género con el entendido de que las mujeres mantienen unidas a las familias (Mushakoji y Pasha, 2008; Truong y Gasper, 2008, 2011; Truong et al., 2014). ${ }^{17}$

${ }_{17}$ Sin embargo, alguna investigación sobre bienestar tal como la del programa de investigación del bienestar en los países en desarrollo de la Universidad de Bath, ha incorporado todos esos elementos. 
Mujeres, género y migración

Diversos trabajos de seguridad humana investigan las implicaciones de los sistemas de roles e ideas de género. No obstante, otros no contemplan el género. Aquellos trabajos —incluso el reporte de la Comisión de Seguridad Humana (CHS, 2003) según Tripp (2013) — usan una noción abstracta de las personas que pasa por alto las cuestiones de género. Los estudios de migración internacional estuvieron concentrados primordial e implícitamente en hombres en edad laboral, excepto en los aislados subcampos de los estudios de refugiados y en los estudios de tráfico de personas. De modo similar, la excelente colección Seguridad Humana y No-Ciudadanos, editada por Alice Edwards y Carla Ferstman, argumenta dentro de los marcos de la legislación de los derechos humanos internacionales y tiene muy poco que decir sobre las mujeres en específico. El enfoque de la seguridad humana y la teoría de la migración han necesitado enriquecerse con el análisis de género y la teoría feminista a fin de hacer justicia a las vulnerabilidades y la explotación particulares de las mujeres migrantes y sobre todo para considerar en serio la reproducción social: biológica, familiar, emocional y cultural (Gasper y Truong, 2014).

Tal como vimos antes, las mujeres migrantes no siempre son las que tienen mayores desventajas, pero al estar sujetas a las normas hegemónicas de género las mujeres que se desplazan tienden a desafiar con frecuencia esas normas y corren el riesgo de ser tratadas como anormales y de haber renunciado a sus derechos (Kapur, 2010). Hemos mencionado la nueva clase global de mujeres trabajadoras domésticas, un enorme grupo cuyo trabajo no es reconocido como trabajo «de verdad» y quienes tienen, por tanto, poca protección. También hemos notado el vacío en lo que concierne a las necesidades de salud sexual y reproductiva de las mujeres; la política migratoria y las prácticas de empleo a menudo se llevan a cabo como si las trabajadoras mujeres fuesen insumos productivos asexuados equivalentes a una lavadora o una plancha. Necesitamos una concepción de las personas reales con necesidades corporales y afectivas fundamentales (Gasper y Truong, 2014).

Los roles característicos de las mujeres y sus responsabilidades en sus familias significan que mayores presiones recaen sobre ellas en las familias 
migrantes. Ellas son los «amortiguadores» de la sociedad (Gasper y Truong, 2010b), tal como se ha visto en varios de los proyectos de investigación presentados en Truong et al. (2014). Pearson y Kusakabe (2012) describen a las mujeres trabajadoras de Birmania en Tailandia — simultáneamente como «trabajadoras, esposas, madres, administradoras del hogar, hijas y apoyo económico para sus familias que permanecen en (o salieron de) su país en crisis»- quienes luchan por «mantenerse ellas mismas cotidianamente y ayudar a los recién nacidos, los jóvenes, los viejos y los enfermos o discapacitados» (Truong, Gasper y Handmaker, 2014: 14). El estudio de Mazumdar y Agnihotri de las millones de trabajadoras rurales informales en la India que son ignoradas por las medidas y las políticas del Estado, «muestra las desesperantes presiones sobre muchas mujeres pobres en tanto la economía rural marginaliza crecientemente algunos grupos, grupos que además tienen el mínimo acceso a los trabajos formales relativamente escasos generados en la economía urbana» (Truong, Gasper y Handmaker, 2014: 16). Serrano Oswald describe cómo en Oaxaca, México, a las mujeres de familias cuyas parejas masculinas han migrado se les exige «mantener la comunidad, los hijos, la cultura, los ancianos, los hogares, la valiosa base agrícola y la infraestructura física y organizativa, así como ayudar a las llegadas y partidas de los migrantes y las demandas adicionales de nuevas actividades económicas [a partir de los ahorros de los migrantes], y a menudo, a esperar un nuevo hijo después de la visita que hace al hogar el esposo» (Truong, Gasper y Handmaker, 2014: 17).

Mientras que el trabajo del enfoque de la seguridad humana en migración requiere una sólida asociación con los estudios de género, la asociación es de mutuo beneficio. Al observar la vida de una persona como un todo, el enfoque de la seguridad humana toma en cuenta las posibles amenazas y los riesgos que las mujeres y las chicas podrían enfrentar simultáneamente (Rubio-Marin y Estrada-Tanck, 2013). Por tanto, el concepto de seguridad humana «ha sido bueno para las académicas feministas en particular, les ha dado un lenguaje para plantear problemáticas acerca de los tipos de violencia inter-personal y estructural que experimentan las mujeres» (Heideman, 2013: 217) en las discusiones que se han realizado sin el enfoque de género y con conceptos orientados de modo implícito hacia lo masculino. 


\section{Enfoque de las capacidades}

Con anterioridad comentamos que el enfoque de la seguridad humana aporta a los estudios migratorios algo útil a partir de la idea de las capacidades, por medio de una representación psicológica más profunda de las personas. Además, incorpora algo esencial en el análisis de la situación de la gente: el tema de la interseccionalidad. Balsera ha abogado por una combinación del análisis de capacidades y de interseccionalidad en el estudio de las vidas de los migrantes y es lo que el enfoque de la seguridad humana justamente pretende hacer. Su estudio investiga las trayectorias de vida y las percepciones de jóvenes ecuatoriano-españoles, hijos de inmigrantes en España. Concluye que el análisis de capacidades debería ampliarse no sólo para investigar individuos, familias o escuelas, sino a «sistemas integrados de opresión» (2014: 60) como un todo, lo que incluye el prestar atención a los procesos de socialización y a las maneras institucionalizadas de pensar y actuar (habitus). Balsera observa la particular importancia de cuestiones relacionadas con la percepción del respeto y el reconocimiento. La falta institucionalizada de respeto y reconocimiento permite explicar cómo en ocasiones los hijos de los inmigrantes - contrariamente a lo esperado - pueden llegar a estar más alienados y excluidos que sus padres, «a pesar de» la escuela y la socialización en el país de destino. De forma consistente con nuestra argumentación previa, vemos el valor de investigar la interacción de diversas fuerzas a través de métodos interpretativos biográfico-narrativos holísticos.

\section{Derechos humanos}

A lo largo de su historia el enfoque de la seguridad humana se ha asociado al trabajo de derechos humanos. Incorpora y depende de valores humanos. Su perspectiva holística ayuda a complementar de distintas maneras la aplicación de esos valores que tradicionalmente se intenta realizar mediante instrumentos legales fijos. De acuerdo con Mushakoji, «la seguridad humana es un concepto clave que busca completar el universalismo europeo de los derechos humanos 
con la investigación existencial de la inseguridad humana, junto con todos sus aspectos particulares y teniendo en cuenta la diversidad de condiciones locales culturales e históricas» (Mushakoji, 2012: 1). El enfoque que particulariza casos y contextos específicos, aunado a la preocupación por las subjetividades, puede resultar una herramienta flexible y sutil para explorar diferentes situaciones. Esto es muy útil en los casos en que la legislación sobre derechos humanos no se ha establecido o no tiene amplia aceptación, como en numerosas situaciones vinculadas con los migrantes y en muchos contextos nacionales. Las normas existentes de derechos humanos contemplan a trabajadores migrantes pero no a otros migrantes como tales, «el marco legal internacional de los derechos de los migrantes no está total ni coherentemente desarrollado» (Estrada-Tanck, 2013: 155). En los ámbitos en los que la normativa de derechos humanos no se ha desarrollado ni se ha consolidado en términos de un consenso nacional, el carácter exploratorio del enfoque de seguridad humana tiene ventajas, pues la discusión y la negociación de las prioridades se encuentran explícitamente abiertas.

Cuando la normativa de derechos humanos ha sido elaborada y consolidada, «el mismo marco analítico de los derechos humanos, con su énfasis en las violaciones individuales, ofrece a menudo un panorama fragmentado de fenómenos que en realidad están interconectados» (Estrada-Tanck, 2013: 153). El análisis de seguridad humana toma en cuenta todo el espectro de amenazas a los derechos humanos de los migrantes, ya sea que provengan de los actores estatales o de otros factores, incluso factores extranacionales; también considera la manera en que las amenazas se interconectan y son en parte estructurales, por ejemplo, en el caso del racismo, la xenofobia y una cultura de violencia contra la mujer. Este enfoque puede «desempeñar un papel integrador como un concepto orientador en la interpretación jurídica [...] actuando como un puente que conecta elementos contenidos en el núcleo de los derechos humanos» (p. 157). En adición, el enfoque nos lleva a preocuparnos por una reforma estructural con el interés de prevenir las violaciones y no simplemente para actuar ex post.

Autores como Mushakoji y Truong indican también que el análisis de seguridad humana ayuda a la perspectiva de los derechos humanos, a evitar ver a las personas como unidades legales autónomas. Se vincula con la ética de 
cuidado, con la sensibilidad a las subjetividades y con la conciencia del potencial de compañerismo con otras personas, así como del potencial de conflicto emocional (Truong y Gasper, 2011).

\section{Conclusión}

El enfoque de seguridad humana ofrece un valioso marco analítico integrador en los estudios migratorios. A su vez, los estudios migratorios aportan mucho a las perspectivas de seguridad humana y de las capacidades (Grønseth, 2013; Gasper y Truong, 2010), aunque aquí no nos hemos concentrado en ello. El artículo ha sido escrito desde una perspectiva general referida a las ideas de seguridad humana; y el panorama de sus contribuciones reales y potenciales en los estudios migratorios se sujeta a mayor refinamiento y mejoramiento. Además, no hemos afirmado que el enfoque de la seguridad humana sea indispensable en cada uno de los varios aportes, más bien hemos sugerido que ofrece una síntesis valiosa de temas relevantes y conexos. Las contribuciones del enfoque son:

1. En primer lugar, ofrece una perspectiva descriptiva y explicativa centrada en la persona, incrustada en un enfoque sistémico, lo que comprende una evaluación sistemática de las amenazas y de las oportunidades para las personas, y una atención especial a las intersecciones de diversos factores y eventos, en particular en situaciones en las que la desposesión se conjuga con la vulnerabilidad.

2. La preocupación en cuanto a la interseccionalidad corresponde a la observación holística de las vidas reales (y muertes). Ello permite una actitud crítica frente a las categorizaciones convencionales de la identidad, de la condición migrante, etcétera, y de las nociones de comunidad y nación, sus simplificaciones y su excesiva mutua exclusión, fluidez/evolución y puntos ciegos

-incluyendo a la gente que se excluye y quizá, por tanto, la más vulnerable (tal como sucede a menudo con los migrantes temporales, circulares y en tránsito y con las trabajadoras domésticas).

3. Promueve un análisis de las estructuras de discriminación y exclusión, que implica a las estructuras de poder y de género, y presta atención a medidas 
preventivas y de reforma. El análisis de política que se deriva tiene la característica de ser transversal.

4. El análisis de seguridad humana podría aportar al análisis de las condiciones de vida una perspectiva más amplia, una concentración en los eventos para complementar el análisis estructural y una atención a las subjetividades. Del mismo modo, se complementa con una gran parte de la investigación sobre bienestar por medio de su concentración en intersecciones, eventos y trayectorias, a la vez que se beneficia y se complementa con el análisis de género.

5. A partir de una evaluación holística de personas de carne y hueso surge una imagen más compleja de la persona y no únicamente como un agente maximizador de ingresos, titular de derechos o aspirante a ellos. El repertorio de comprensiones engloba necesidades corporales y psicológicas, motivaciones y sentimientos: imperativos de reproducción social, corporal y psicológica, y muerte; miedos, sentimientos de dignidad y respeto, reconocimiento, asociación y cuidado, necesidades percibidas de pertenencia (y de desafiliación; De Haas, 2014); seguridad e inseguridad emocional, esquemas mentales e intuiciones; y el compromiso percibido con la nación o la comunidad. El repertorio es bastante compatible con la perspectiva de género. Busca atender a la totalidad de un individuo, de una edad particular, género, etnicidad, cultura y trayectoria de vida y no a una imagen convencional del migrante. El centrarse en las personas requiere y conduce a una atención comparable respecto del residente nativo (véase UNESCO, 2007).

6. La comprensión más enriquecida del individuo y el tratamiento de la interseccionalidad y del «sistema integrado de opresión» muestra la forma en que el análisis de seguridad humana puede enriquecer las aplicaciones del enfoque de las capacidades en los estudios migratorios.

7. Se abre una perspectiva global para la explicación que hace factible ver cómo el movimiento de capitales contribuye al movimiento de las personas. Dicha perspectiva global se refleja en la cuestión de la seguridad común que no es posible producir seguridad de modo sostenido para uno a través de la creación de inseguridad para otros. Por tanto, se requiere una comprensión sobre la base de mayor información acerca de uno mismo. Cada una de esas 
ideas refleja a su vez la cuestión de la interconexión completa: la «dimensión de la conectividad» en el discurso de la seguridad humana.

8. El esquema de la seguridad humana también adopta una perspectiva global referente a la evaluación, que implica al mismo tiempo una concentración en la persona a escala mundial, lo que es una parte de su "dimensión de equidad». Asume con seriedad los valores de los derechos humanos y este compromiso conlleva la descripción a partir de un enfoque en las personas. Los estudios de seguridad humana se sustentan en un compromiso con valores más claro que el de otros estudios migratorios: con el valor que tiene cada persona en todo el mundo, con sus necesidades y derechos básicos, incluyendo los de dignidad y expresión. Al combinarse con la perspectiva global para la explicación se llega a los principios de «todos son afectados» $\mathrm{y}$ «todos dependen» con relación a la gobernanza migratoria y a las cuestiones de fortalecimiento del empoderamiento de los migrantes de su representación y expresión: de modo que los migrantes estén en la agenda y en la mesa de discusión.

9. Un esquema de seguridad humana aporta algo a los enfoques de derechos humanos en la migración al enfatizar múltiples influencias que se interconectan, como factores estructurales, y al incluir el interés por las subjetividades y por las particularidades de cada caso, no sólo las reconocidas en instrumentos legales preestablecidos al ser más flexible, al no absolutizar los derechos, y por medio de una apertura a la ética del cuidado.

En suma, un enfoque de seguridad humana puede ayudarnos en la exploración de las relaciones entre migración, nuevas precariedades y nacionalismos que resurgen en un mundo cada vez más interconectado.

\section{Bibliografía}

ADDAMS, J. (1907), Newer Ideals of Peace, New York, Macmillan.

AJAYI, S.I. and L. Ndikumana (eds.) (2014), Capital Flight from Africa: Causes, Effects and Policy Issues, Oxford, Oxford University Press.

Arango, J. (2000), "Global Trends and Issues - Explaining Migration: A Critical View», International Social Science Journal, vol. 52, no. 3. 
BAGCHI, A.K. (2008), «Immigrants, Morality and Neoliberalism», Development and Change, vol. 39, no. 2, pp. 197-218. (2011), "Migration, Morality and Finance», in Truong and Gasper (eds.) (2011), Transnational Migration and Human Security, Heidelberg, Springer.

BAKeWelL, O. (2008), "Keeping Them in Their Place: The ambivalent relationship between development and migration in Africa», Third World Quarterly, vol. 29.

BalserA, M. Ron (2014), «Young Migrants' Aspirations, Expectations and Perspectives of Well-Being investigated using Biographical Narratives, the Capability Approach and Intersectionality», $\mathrm{PhD}$ thesis, Faculty of Education, Bielefeld University.

BARRY, F. (2014), "Capital flight, safe havens and secrecy jurisdictions», in Ajayi and Ndikumana (eds.), Capital Flight from Africa: Causes, Effects and Policy Issues, Oxford, Oxford University Press.

Benton, G. (2013), «Foreword», in Pain H. H., Chinese Whispers: The True Story Behind Britain's Hidden Army of LabourI, London, Penguin.

BurgeSS, J.P. et al. (2007), Promoting Human Security: Ethical, normative and educational frameworks in Western Europe, Paris, United Nations Educational, Scientific and Cultural Organization.

Campillo Carrete, B. and Gasper, D. (2011), "Managing Migration in the IOM's World Migration Report 2008», in Truong \& Gasper (eds.) (2011), Transnational Migration and Human Security, Heidelberg, Springer, pp. 117-132.

Commission on Human Security (2003), Human Security Now, New York, UN Secretary-General's Commission on Human Security.

De HAAS, H. (2010), «Migration and Development: A Theoretical Perspective», International Migration Review, vol. 44, no. 1. (2014), «Migration Theory: Quo Vadis?», Working Paper 100, International Migration Institute, Oxford.

Drèze, J. and Sen, A. (1989), Hunger and Public Action, Oxford, Clarendon Press.

Düwell, M., J. Braarvig, R. Brownsword, D. Mieth (eds.) (2014), The Cambridge Handbook of Human Dignity: Interdisciplinary Perspectives, Cambridge University Press.

EDWArds, A. and Ferstman, C. (eds.) (2010), Human Security and Non-Citizens, Cambridge, Cambridge University Press. 
ERIKSEN, T.H. et al. (2010), A world of insecurity: Anthropological perspectives on human security, London \& New York, Pluto.

ERSKINE, T. (2000) "Embedded cosmopolitanism and the case of war: restraint, discrimination and overlapping communities», Global Society, vol. 14, no. 4.

ESTRADA-TANCK, D. (2013), «Human Security and the Human Rights of Undocumented Migrants», European Journal of Social Security, vol. 15, no. 2.

(2015), "Human Security and the Human Rights of Labour Migrants in the Americas», in M. Panizzon, G. Zürcher, E. Fornalé (eds.), The Palgrave Handbook of International Labour Migration, Basingstoke, Palgrave Macmillan.

Fraser, N. (2008), Scales of Justice. Reimagining Political Space in a Globalizing World, Cambridge, Polity Press.

GASPER, D. (2005), «Beyond The Inter-National Relations Framework: An Essay In Descriptive Global Ethics», J. of Global Ethics, vol. 1, no. 1. (2010), «The Idea of Human Security», in K. O’Brien, A.L. St.Clair, B. Kristoffersen (eds.), Climate Change, Ethics and Human Security, Cambridge, Cambridge University Press. (2011), «International Migration, Well-Being and Transnational Ethics», in Truong \& Gasper (eds.) (2011), Transnational Migration and Human Security, Heidelberg, Springer.

(2014), «Human Security Analysis as a Framework for Value-Oriented Governance: the example of climate change», International J. of Social Quality, vol. 4, no. 2.

GASPER, D., O.A. Gomez (2014), «Evolution of thinking and research on human security and personal security 1994-2013", New York, UNDP Occasional Paper, in http:// hdr.undp.org/en/content/evolution-thinking-and-research-human-and -personal-security-1994-2013.

(2015), «Human Security Thinking in Practice. «Personal Security», «Citizen Security and Comprehensive Mappings», Contemporary Politics, vol. 21, no. 1.

GASPER, D., T.D. Truong (2010a), «Movements Of The :Wes: International and Transnational Migration and the Capabilities Approach", J. of Human Development and Capabilities, vol. 11, no. 2. 
(2010b), "Development Ethics through the Lenses of Caring, Gender and Human Security", in S. Esquith and F. Gifford (eds.), Capabilities, Power and Institutions, Pennsylvania, Pennsylvania State University Press.

(2014), «Women in motion in a world of nation-states, market forces, and gender power relations», in Truong et al. (eds.) (2014), Migration, Gender and Social Justice: Perspectives on human insecurity, Heidelberg, Springer, in http://link.springer. com/book/10.1007/978-3-642-28012-2.

GLICK SCHILLER, N. (2010), "A global perspective on transnational migration: Theorising migration without methodological nationalism», in Baubock, R. and T. Faist (eds.), Diaspora and Transnationalism: Concepts, Theories and Methods, Amsterdam, Amsterdam University Press.

Gomez, O. and Gasper, D. (2013), «Human Security: A Thematic Guidance Note for Regional and National Human Development Report Teams», New York, Human Development Report Office, UNDP, in http://hdr.undp.org/sites/default/files/ human_security_guidance_note_r-nhdrs.pdf

GORE, C. (1996), «Methodological Nationalism and the Misunderstanding of East Asian Industrialization», European J. of Development Research, vol. 8, no. 1.

GrøNSETH, A.S. (ed.) (2013), Being Human, Being Migrant. Senses of Self and Well-Being, New York, Berghahn.

HAa, M. (1999), Reflections on Human Development, Delhi, Oxford University Press.

HARADA, T. with K. Kimura (2011), «Human or Public: The Referents of Security in Discourses on Migrants in Japan", in Truong and Gasper (eds.) (2011), Transnational Migration and Human Security, Heidelberg, Springer.

HeIDEMAN, L. (2013), "The vulnerable protecting the vulnerable», in Tripp, Ferree, \& Ewig (eds.), Gender, violence, and human security: Critical feminist perspectives, New York, New York University Press.

Kapur, R. (2010), Makeshift Migrants and Law: Gender, Belonging and the Legal Regulation of the Migrant, New Delhi, Routledge.

KaYe, J. (2010), Moving Millions: how coyote capitalism fueled global immigration, New York, Wiley.

KojimA, Y. (2011), «Migrant Women and Their Vulnerability in the Trafficking-Migration Continuum: Evidence from Asia», in Truong and Gasper (eds.) (2011), Transnational Migration and Human Security, Heidelberg, Springer. 
LeOn-Ross, P., G. Summerfield and M. Arends-Kuenning (2013), «Exploring Latina/ Latino Migrants' Adaptation to the Economic Crisis in the US Heartland: A Capability Approach», J. of Human Development and Capabilities, vol. 14, no. 2.

LESTER, E. (2010), «Socio-economic rights, human security and survival migrants: Whose rights? Whose security?», in Edwards and Ferstman (eds.), Human Security and Non-Citizens, Cambridge: Cambridge University Press.

MahleR, S.J. and Pessar, P.R. (2001), "Gendered Geographies of Power: Analyzing Gender Across Transnational Spaces», Identities, vol. 7, no. 4.

MALAVISI, A. (2015), «The need for an effective development ethics», J. of Global Ethics, vol. 10, no. 3 .

MAZUMDAR, I. and I. Agnihotri (2014), «Traversing Myriad Trails: Tracking Gender and Labour Migration across India», in Truong et al. (eds.) (2014), Migration, Gender and Social Justice: Perspectives on human insecurity, Heidelberg, Springer.

MCCRUdDen, C. (ed.) (2013), Understanding Human Dignity, Oxford University Press.

Mine, Y. (2011), «Migration Regimes and the Politics of Insiders/Outsiders: Japan and South Africa as Distant Mirrors», in Truong and Gasper (eds.) (2011), Transnational Migration and Human Security, Heidelberg, Springer.

MURPHY, C. (2015), «Dignity, Human Security and Global Governance», J. of Human Security Studies, vol. 4, no. 1.

MUSHAKoJI, K. (2011), «State and Immigrant Diaspora Identity in Contemporary Japan: From a Developmentalist National Ethic towards a Multicultural Development Ethic of Common Human Security», in Truong and Gasper (eds.) (2011), Transnational Migration and Human Security, Heidelberg, Springer.

(2012), «Three Reasons Why We Should Study Human Security», J. of Human Security Studies, vol. 1, no. 1.

Mushakoji, K. and Pasha, M.K. (eds.) (2008), Human (In)Security in the Networks of Global Cities, Kasugai City, Japan, Chubu University and Centre for Human Security Studies.

Oberleitner, G. (2012), «Human Security», in D. Forsythe (ed.), Encyclopedia of Human Rights, New York, Springer.

OBEROI, P. (2010), «Empowering migrants: human security, human rights, and policy», in Edwards and Ferstman (eds.), Human Security and Non-Citizens, Cambridge, Cambridge University Press. 
O'BRIEn, K., and Leichenko, R. (2007), "Human Security, Vulnerability and Sustainable Adaptation», HDRO Occasional Paper 2007/9, New York, United Nations Development Programme.

O'NeILl, O. (1996), Towards Justice and Virtue, Cambridge, Cambridge University Press. PAI, H.H. (2008), Chinese Whispers: The True Story Behind Britain's Hidden Army of LabourI, London, Penguin. (2013), Scattered Sand. The Story of China's Rural Migrants, London, Verso.

PAlme, O. et al. (1982), Common Security: A Blueprint for Survival, The Independent Commission on Disarmament and Security Issues.

Pearson, R., Kusakabe, K. (2012), Thailand's Hidden Workforce: Burmese Migrant Women Factory Workers, London, Zed.

PeSSAR, P. and S.J. Mahler (2003), «Transnational Migration: Bringing Gender In», International Migration Review, vol. 37, no. 3.

PoGge, T. (2005), «Recognised and Violated by International Law: the Human Rights of the Global Poor», Leiden Journal of International Law, vol. 18, no. 4.

RUBIO-MARIN, R. and Estrada-Tanck, D. (2013), «Violence against women, human security, and human rights of women and girls: reinforced obligations in the context of structural vulnerability», in Tripp, Ferree and Ewig (eds.), Gender, violence, and human security: critical feminist perspectives, New York, New York University Press.

SEN, A.K. (1981), Poverty and Famines, Oxford, Clarendon.

SERRANO OSWALD, S.E. (2014), «Migration, Woodcarving, and Engendered Identities in San Martín Tilcajete, Oaxaca, Mexico», in Truong et al. (eds.) (2014), Migration, Gender and Social Justice: Perspectives on human insecurity, Heidelberg, Springer.

SHANI, G. (2015), "Dignity as a Culturally Contested Concept», J. of Human Security Studies, vol. 4, no. 1.

SHARMA, J.R. (2008), «Practices of Male Labour Migration from the Hills of Nepal to India», Gender, Technology and Development, vol. 12, no. 3.

SiNATTI, G. and D. Gasper (2015), «Migrant integration and transnational linkages: beyond nationalist presumptions and towards a human security framing», Paper to ASEN conference, London School of Economics. 
TAHA, N., Siegmann, K.A. and Messkoub, M. (2015), «How portable is social security for migrant workers? A review of the literature», International Social Security Review, vol. 68, no. 1.

TANDIAN, A. and S. Bergh (2014), «From Temporary Work in Agriculture to Irregular Status in Domestic Service: the Transition and Experiences of Senegalese Migrant Women in Spain», in Truong et al. (eds.) (2014), Migration, Gender and Social Justice: Perspectives on human insecurity, Heidelberg, Springer.

TRIPP, A.M. (2013), "Toward a gender perspective on human security», in Tripp, Ferree and Ewig (eds.), Gender, violence, and human security: Critical feminist perspectives, New York, New York University Press.

TRIPP, A. M., M. M. Ferree and C. Ewig (eds.) (2013), Gender, violence, and human security: Critical feminist perspectives, New York, New York University Press.

TruOnG, T.D. and Gasper, D. (eds.) (2008), Trans-Local Livelihoods and Connections, special issue, Gender, Technology and Development, vol. 12, no. 3. (2011), Transnational Migration and Human Security, Heidelberg, Springer.

TruonG, T.D., D. Gasper, J. Handmaker (2014), «Migration, Gender, Social Justice, and Human Insecurity», in Truong et al. (eds.) (2014), Migration, Gender and Social Justice: Perspectives on human insecurity, Heidelberg, Springer.

Truong, T.D., D. Gasper, J. Handmaker and S. Bergh (eds.) (2014), Migration, Gender and Social Justice: Perspectives on human insecurity, Heidelberg, Springer, in http:// link.springer.com/book/10.1007/978-3-642-28012-2 (open-access).

TRuONG, T.D., M.L. Marin and A. Quesada-Bondad (2014), «Intersectionality, Structural Vulnerability, and Access to Sexual and Reproductive Health Services», in Truong et al. (eds.) (2014), Migration, Gender and Social Justice: Perspectives on human insecurity, Heidelberg, Springer.

VIETTI, F., Scribner, T. (2013), «Human Insecurity: Understanding International Migration from a Human Security Perspective», J. of Migration and Human Security, vol. 1, no.1.

WeRTHES, S. and Debiel, T. (2006), «Human security on foreign policy agendas», in T. Debiel and S. Werthes (eds.), Human Security on Foreign Policy Agendas: Changes, Concepts, Cases, Duisburg, University of Duisburg-Essen. 
WrIGHT, K. (2010), «It's a Limited Kind of Happiness: Barriers to Achieving Human Well-being among Peruvian Migrants in London and Madrid», Bulletin of Latin American Research, vol. 29, no. 3. (2011), «Constructing Migrant Wellbeing: An Exploration of Life Satisfaction Amongst Peruvian Migrants in London", Journal of Ethnic and Migration Studies, vol. 37, no. 9.

(2012), International Migration, Development and Human Wellbeing, Palgrave Macmillan.

WrigHT, K. and R. Black (2011), «International Migration And The Downturn: Assessing The Impacts Of The Global Financial Downturn On Migration, Poverty And Human Well-Being», J. of International Development, vol. 23.

ZHU, Y. and L. Lin (2014), «From Integration into Cities» to (An Integrated Society): Women Migrants' Needs and Rights in Fujian Province, China», in Truong et al. (eds.) (2014), Migration, Gender and Social Justice: Perspectives on human insecurity, Heidelberg, Springer. 